https://doi.org/10.15407/ujpe65.5.393

V.I. GRYTSAY, ${ }^{1}$ A.G. MEDENTSEV ${ }^{2}$ A.YU. ARINBASAROVA ${ }^{2}$

${ }^{1}$ Bogolyubov Institute for Theoretical Physics, Nat. Acad. of Sci. of Ukraine (14b, Metrolohichna Str., Kyiv 03680,Ukraine; e-mail: vigrytsay@gmail.com)

${ }^{2}$ G.K. Skryabin Institute of Biochemistry and Physiology of Microorganisms of the RAS (5, Prosp. Nauki, Pushchino, Moscow region, Russian Federation;

e-mail: medentsev-ag@rambler.ru)

\title{
AUTOOSCILLATORY DYNAMICS IN A MATHEMATICAL MODEL OF THE METABOLIC PROCESS IN AEROBIC BACTERIA. INFLUENCE OF THE KREBS CYCLE ON THE SELF-ORGANIZATION OF A BIOSYSTEM
}

\begin{abstract}
We have modeled the metabolic process running in aerobic cells as open nonlinear dissipative systems. The map of metabolic paths and the general scheme of a dissipative system participating in the transformation of steroids are constructed. We have studied the influence of the Krebs cycle on the dynamics of the whole metabolic process and constructed projections of the phase portrait in the strange attractor mode. The total spectra of Lyapunov exponents, divergences, Lyapunov's dimensions of the fractality, Kolmogorov-Sinai entropies, and predictability horizons for the given modes are calculated. We have determined the bifurcation diagram presenting the dependence of the dynamics on a small parameter, which defines system's physical state.

Ke ywords: mathematical model, metabolic process, self-organization, deterministic chaos, strange attractor, bifurcation.
\end{abstract}

\section{Introduction}

We will study the causes for the appearance of an autooscillatory dynamics in the metabolic process running in aerobic bacteria which was observed experimentally in a bioreactor with Arthrobacter globiformis cells $[1-5]$. The consideration is carried on with the help of the synergetic method of modeling of the metabolic processes developed in works by V.I. Grytsay [6-33]. The application of this method will allow us to consider the self-organization and the dynamic chaos in the metabolic processes in cells and in organism as a whole and to establish the physical laws for their vital processes.

(C) V.I. GRYTSAY, A.G. MEDENTSEV, A.YU. ARINBASAROVA, 2020
The mentioned microorganism is referred to oxygen-breathing bacteria arisen 2.48 bln years ago. Due to the evolution of the metabolic processes of protobionts, the microorganisms not consuming oxygen transited to oxygen-breathing bacteria with their subsequent evolution to eukaryotes. The consideration of a specific biochemical process of transformation of steroids allows us to use the experimentally determined parameters in the construction of a model and to conclude about structural-functional connections under conditions of the self-organization in the vital activity of cells. The relative simplicity of the given metabolic process of bacteria under study gives possibility to model the whole metabolic process in a cell as an open dissipative system, in which two main systems (namely, the system of transformation of a 


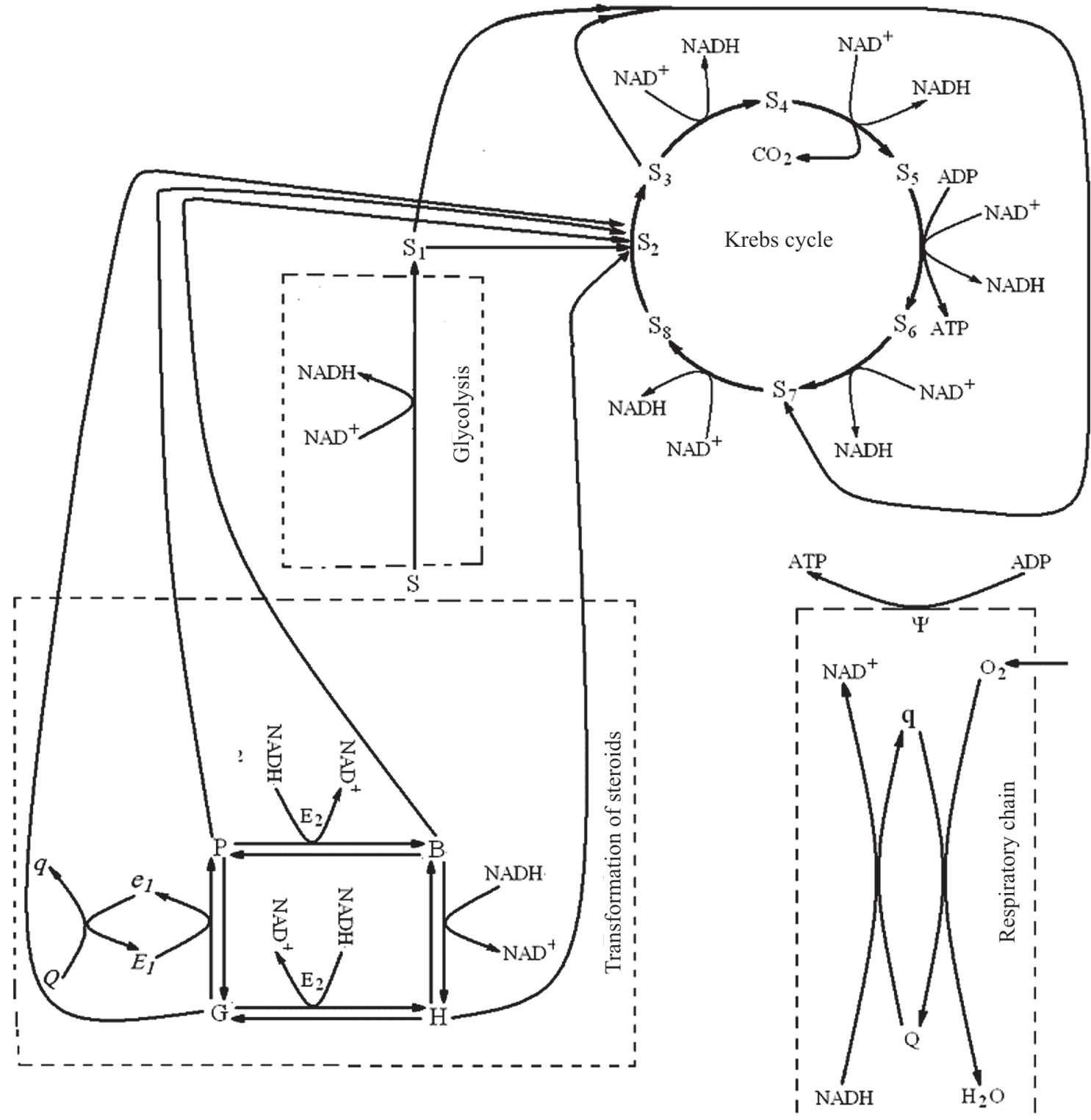

Fig. 1. Map of metabolic paths of a cell Arthrobacter globiformis

substrate and the respiratory chain) necessary for its life are self-organized.

\section{Mathematical Model}

In order to develop a mathematical model of the process of transformation of steroids by aerobic bacteria Arthrobacter globiformis, we use the map of their metabolic paths at the transformation of steroids
(Fig. 1) obtained as a result of the processing of experimental data $[2,3]$.

Since we consider only the process of transformation of steroids, we separate the localized dissipative system of transformation of steroids, which interacts with other metabolic processes in a cell. Its general scheme is presented in Fig. 2.

Based on the scheme in Fig. 2, we developed a mathematical model of the metabolic process in a cell

ISSN 2071-0194. Ukr. J. Phys. 2020. Vol. 65, No. 5 
in the following form:

$$
\begin{aligned}
& \frac{d G}{d t}=\frac{G_{0}}{N_{3}+G+\gamma_{2} \psi}-l_{1} V\left(E_{1}\right) V(G)-\alpha_{3} G \\
& \frac{d P}{d t}=l_{1} V\left(E_{1}\right) V(G)-l_{2} V\left(E_{2}\right) V(N) V(P)-\alpha_{4} P \\
& \frac{d B}{d t}=l_{2} V\left(E_{2}\right) V(N) V(P)-k_{1} V(\psi) V(B)-\alpha_{5} B \\
& \frac{E_{1}}{d t}=E_{10} \frac{G^{2}}{\beta_{1}+G^{2}}\left(1-\frac{P+m N}{N_{1}+P+m N}\right)- \\
& -l_{1} V\left(E_{1}\right) V(G)+l_{4} V\left(e_{1}\right) V(Q)-a_{1} E_{1} \\
& \frac{d e_{1}}{d t}=-l_{4} V\left(e_{1}\right) V(Q)+l_{1} V\left(E_{1}\right) V(G)-\alpha_{1} e_{1} \\
& \frac{d Q}{d t}=6 l V(2-Q) V\left(O_{2}\right) V^{(1)}(\psi)- \\
& -l_{6} V\left(e_{1}\right) V(Q)-l_{7} V(Q) V(N) \\
& \frac{d O_{2}}{d t}=\frac{O_{20}}{N_{5}+O_{2}}-l V(2-Q) V\left(O_{2}\right) V^{(1)}(\psi)-\alpha_{7} O_{2}
\end{aligned}
$$

$\frac{d E_{2}}{d t}=E_{20} \frac{P^{2}}{\beta_{2}+p^{2}} \frac{N}{\beta+N}\left(1-\frac{B}{N_{2}+B}\right)-$ $-l_{10} V\left(E_{2}\right) V(N) V(P)-\alpha_{2} E_{2}$,

$\left.\frac{d N}{d t}=-l_{2} V\left(E_{2}\right) V(N) V(P)-l_{7} V(Q) V(N)\right)+$

$+k_{2} V(B) \frac{\psi}{K_{10}+\psi}+\frac{N_{0}}{N_{4}+N}-\alpha_{6} N$,

$\frac{d \psi}{d t}=l_{5} V\left(E_{1}\right) V(G)+l_{8} V(N) V(Q)-\alpha \psi$,

where $V(X)=X /(1+X) ; V^{(1)}(\psi)=1 /\left(1+\psi^{2}\right)$; $V(X)$ is a function describing the adsorption of the enzyme in the region of a local bond; and $V^{(1)}(\psi)$ is a function characterizing the influence of a kinetic membrane potential on the respiratory chain.

In the modeling, it is convenient to introduce the following dimensionless parameters: $l=l_{1}=k_{1}=$ $=0.2 ; l_{2}=l_{10}=0.27 ; l_{5}=0.6 ; l_{4}=l_{6}=0.5$; $l_{7}=1.2 ; l_{8}=2.4 ; k_{2}=1.5 ; E_{10}=3 ; \beta_{1}=2 ;$ $N_{1}=0.03 ; m=2.5 ; \alpha=0.033 ; a_{1}=0.007 ; \alpha_{1}=$ $=0.0068 ; E_{20}=1.2 ; \beta=0.01 ; \beta_{2}=1 ; N_{2}=0.03$; $\alpha_{2}=0.02 ; G_{0}=0.019 ; N_{3}=2 ; \gamma_{2}=0.2 ; \alpha_{5}=0.014$; $\alpha_{3}=\alpha_{4}=\alpha_{6}=\alpha_{7}=0.001 ; O_{20}=0.015 ; N_{5}=0.1$; $N_{0}=0.003 ; N_{4}=1 ; K_{10}=0.7$.

Equations (1)-(9) describe variations in the concentrations of hydrocortisone $(G)(1)$; prednisolone ISSN 2071-0194. Ukr. J. Phys. 2020. Vol. 65, No. 5

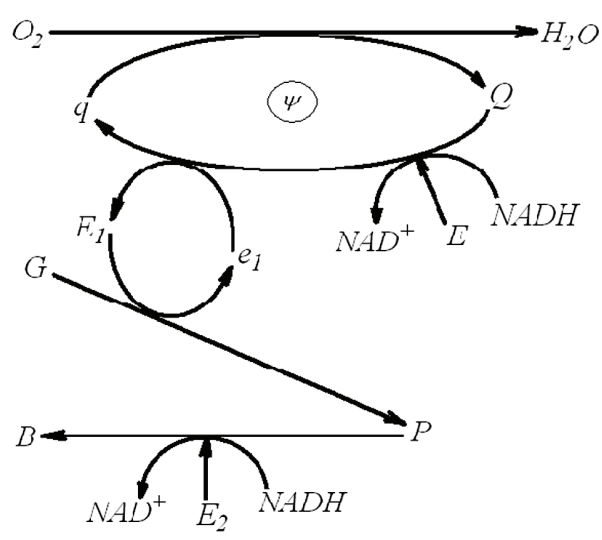

Fig. 2. General scheme of the process of transformation of steroids by a cell Arthrobacter globiformis

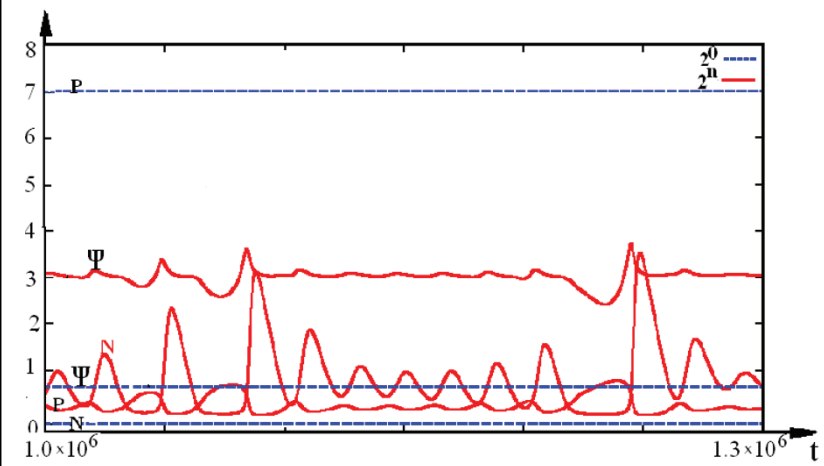

Fig. 3. Kinetic curves for some variables of the stationary $2^{0}$ $\left(N_{0}=0\right)$ and autooscillatory $2^{n}\left(N_{0}=0.00366\right)$ modes

$(P)(2) ; 20 \beta$-oxyderivative of prednisolone $(B)(3)$; oxidized form of 3-ketosteroid- $\Delta^{\prime}$-dehydrogenase $\left(E_{1}\right)$ (4); reduced form of 3-ketosteroid- $\Delta^{\prime}$-dehydrogenase $\left(e_{1}\right)$ (5); oxidized form of the respiratory chain $(Q)$ (6); oxygen $\left(\mathrm{O}_{2}\right)(7) ; 20 \beta$-oxysteroid-dehydrogenase $\left(E_{2}\right)(8)$; and $(9) N A D \cdot H$ (reduced form of nicotinamide adenine dinucleotide) $(N)$. Equation (10) shows a change in the kinetic membrane potential $(\psi)$.

The reduction of parameters of the system to the dimensionless form was presented in $[2,3]$.

The calculations according to the given mathematical model (1)-(10) were carried out with the application of the theory of nonlinear differential equations [34].

The analogous modeling of bioprocesses was realized in a lot of works (see, e.g., [35-40]).

\section{Results of the Study}

Within the constructed mathematical model (1)(10), we performed the computational experiments, 

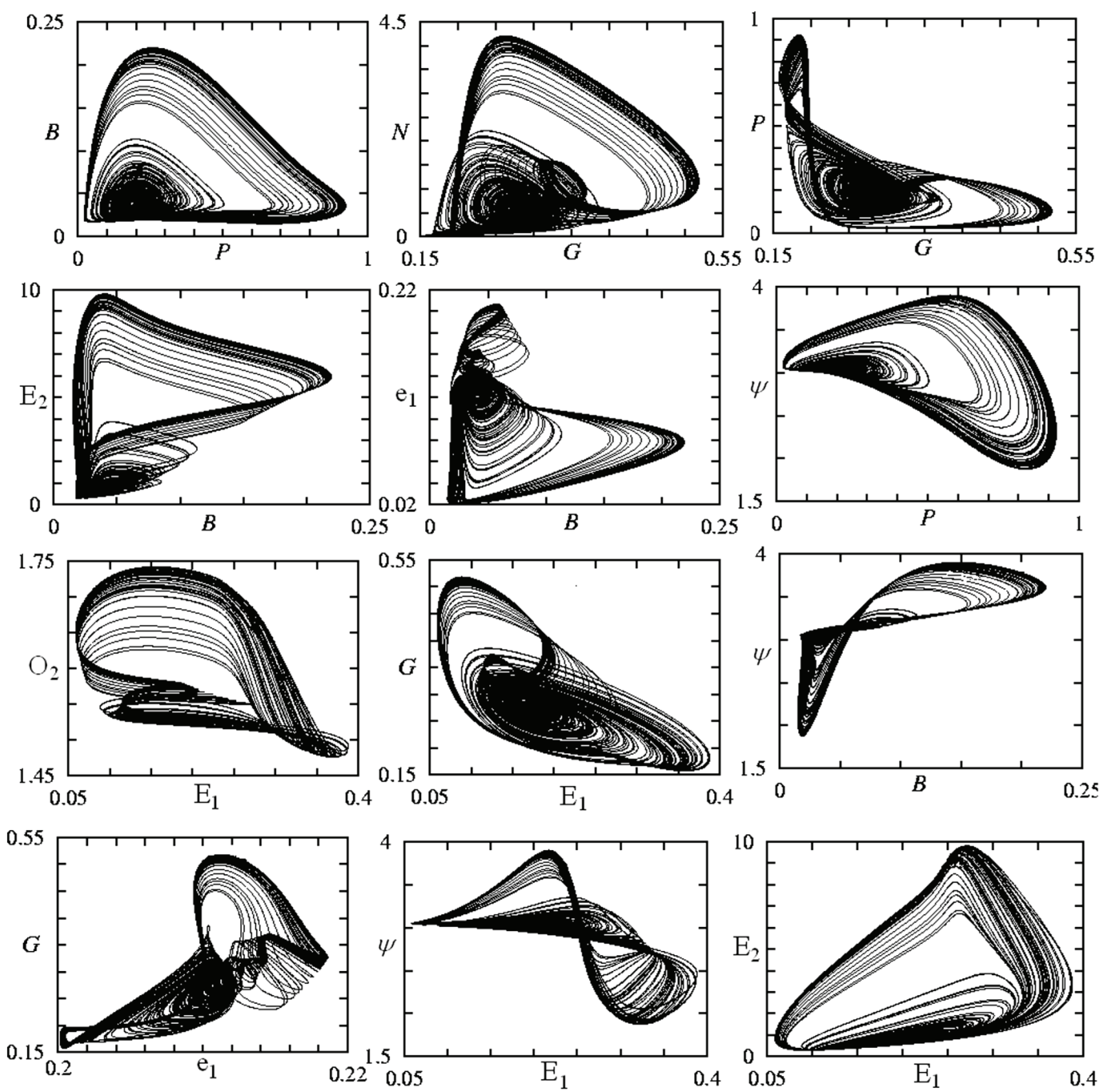

Fig. 4. Projections of the phase portrait of a strange attractor arising at $N_{0}=0.00344$

by studying the dependence of the kinetics of the metabolic process in a cell on the Krebs cycle [26]. These both processes are coupled with each other by the level of NADH $(\mathrm{N})$. The variation in the amount of this metabolite during the Krebs cycle affects the respiratory chain and the activity of enzyme $E_{2}$ (see Fig. 2). In Fig. 3, we present the kinetics of some components in two modes: for $N_{0}=0$ and $N_{0}=0.0366$. The change in this parameter causes the transition from the stationary mode $2^{0}$ to the autooscillatory one $2^{n}$. Such modes were observed in the experiment with a bioreactor $[4,5]$. However, the nature of such oscillations was not clarified, though some hypotheses were advanced [5].
In the investigation of the physical dynamical pattern of the mentioned oscillations in cells, we tested the observed autooscillations for the stability by Lyapunov. For different values of $N_{0}$, we calculated the total spectra of Lyapunov exponents (see Table), which enabled us to establish the dynamics of the process. The form of constructed attractors characterizes the mode of the self-organization of the metabolic process in a cell or the mode of dynamic chaos as the transient mode describing the adaptation of the metabolism to a change in the nutrition of a cell from the external medium. By the determined values of Lyapunov exponents for strange attractors, we calculated the Lyapunov dimensions of their fractalities, 

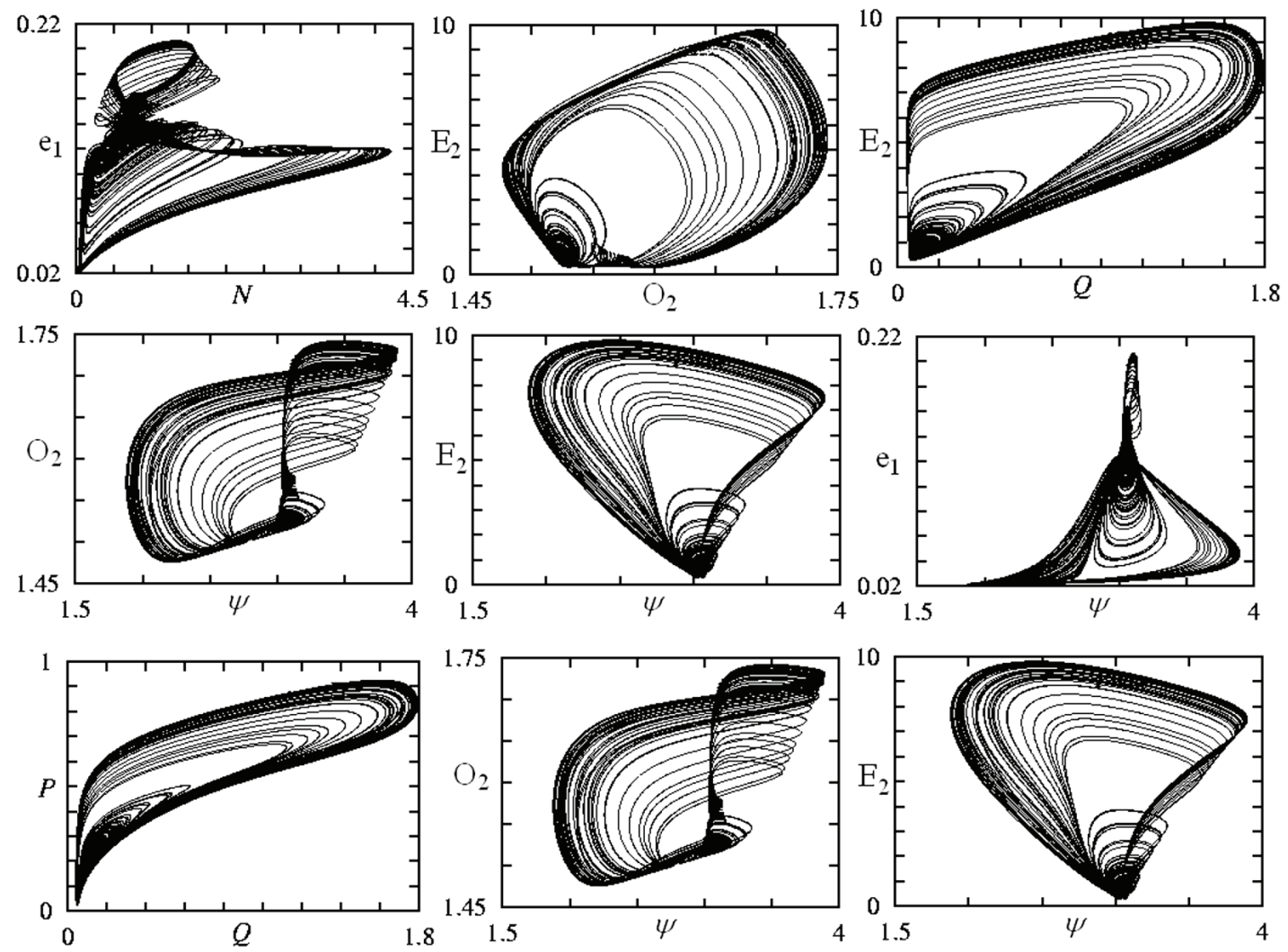

Fig. 5. Projections of the phase portrait of a strange attractor arising at $N_{0}=0.00344$

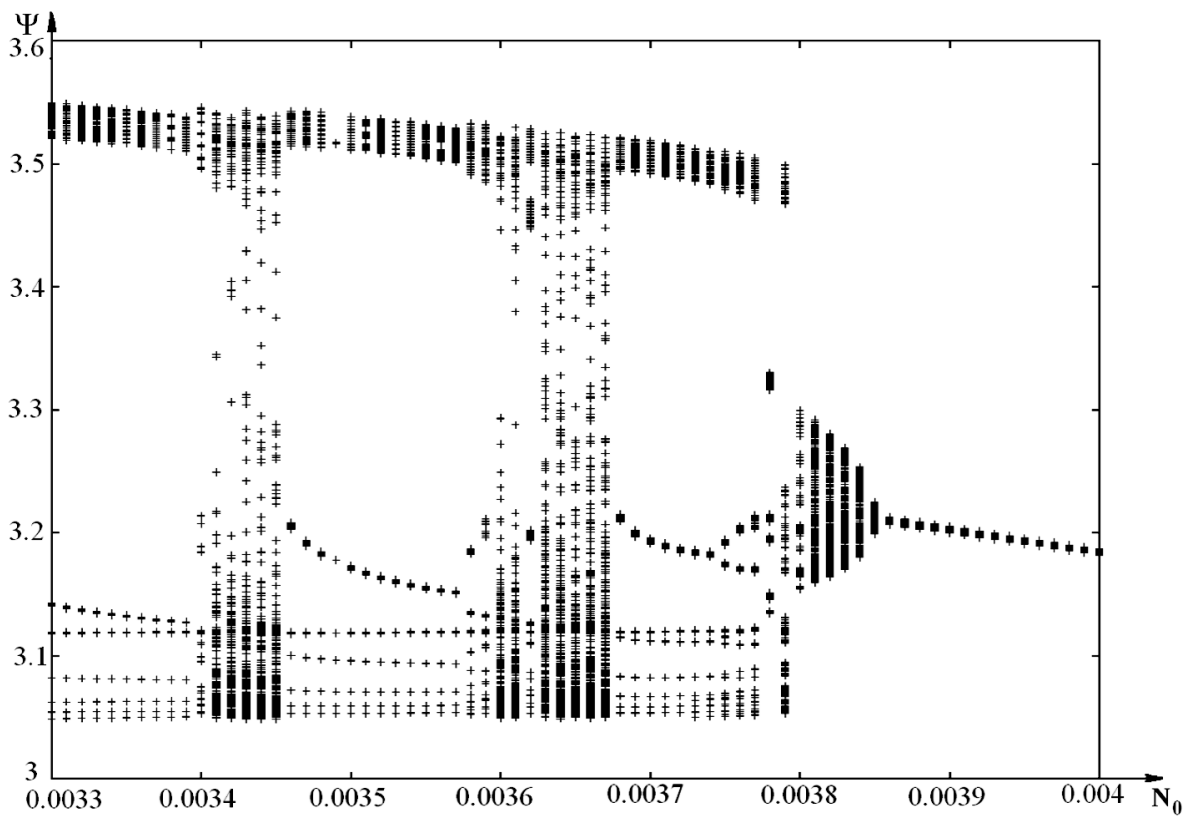

Fig. 6. Bifurcation diagram of the dependence of the form of attractors of the dynamic process on the parameter $N_{0}$ 
Total spectra of Lyapunov exponents $\left(\lambda_{1}-\lambda_{10}\right)$, divergences $(\Lambda)$, Kolmogorov-Sinai entropies $(h)$, foresight horizons $\left(t_{\text {min }}\right)$, and Lyapunov dimensions of strange attractors $\left(D_{F_{r}}\right)$ for the dynamic modes at different $N_{0}$

\begin{tabular}{|c|l|l|l|l|}
\hline \multirow{2}{*}{$\begin{array}{c}\text { Lyapu- } \\
\text { nov's }\end{array}$} & \multicolumn{4}{|c|}{$N_{0}$} \\
\cline { 2 - 5 } indices & 0.003 & 0.00328720 & \multicolumn{1}{|c|}{0.0043} & \multicolumn{1}{|c|}{0.00344} \\
\cline { 2 - 5 } & \multicolumn{3}{|c|}{ Structure } \\
\cline { 2 - 5 } & \multicolumn{3}{|c|}{$2^{n}$} & $2^{x}$ \\
\hline$\lambda_{1}$ & -0.0000056 & 0.0000280 & 0.0005342 & 0.000607 \\
$\lambda_{2}$ & -0.004731 & -0.000586 & 0.000019 & 0.000019 \\
$\lambda_{3}$ & -0.0049847 & -0.0046497 & -0.0047941 & -0.00478731 \\
$\lambda_{4}$ & -0.0083491 & -0.0082351 & -0.0079388 & -0.00776693 \\
$\lambda_{5}$ & -0.0230134 & -0.0237059 & -0.0230698 & -0.023414386 \\
$\lambda_{6}$ & -0.0302575 & -0.0290098 & -0.0292015 & -0.0289861 \\
$\lambda_{7}$ & -0.079155 & -0.0796078 & -0.80446039 & -0.080484059 \\
$\lambda_{8}$ & -0.0870153 & -0.0860939 & -0.0833784 & -083210056101 \\
$\lambda_{9}$ & -0.1807851 & -1.7927866 & -0.1787882 & -0.178729 \\
$\lambda_{10}$ & -0.5214070 & -0.5136290 & -0.5147199 & 0.5145829 \\
$\Lambda$ & -0.9354453 & -0.9245716 & -0.9217877 & -0.921326 \\
$h$ & & & 0.000549 & 0.000627 \\
$t_{\mathrm{min}}$ & & & 1821161 & 1595914 \\
$D_{F_{r}}$ & & & 2.114537 & 2.13088 \\
\hline
\end{tabular}

Kolmogorov-Sinai entropies, and foresight horizons [35]. On the basis of those data, we may judge about the structure of strange attractors. Some their projections are shown in Figs. 4 and $5\left(N_{0}=0.00344\right)$.

Then we calculated the bifurcation diagram presenting the dynamics of the metabolic process as a function of $N_{0}$ (see Fig. 6). There, the transitions from the 1-fold mode to multiple modes, as well as strange attractors, are clearly seen.

\section{Conclusions}

A mathematical model of the open dissipative system with localized metabolic process involving aerobic bacteria is presented. The general map of its metabolic paths is constructed.

The synergetic method to study the self-organization and dynamical chaos in metabolic processes in a cell and the whole organism is developed.

In adreement with experimental data, we have determined the map of paths of the metabolic process running in aerobic bacteria and the general scheme of a dissipative system of transformation of steroids. Using the constructed mathematical model, we have studied the dependence of the dynamics on a change in the small parameter of the Krebs cycle and found the modes of autooscillations and strange attractors. The total spectra of Lyapunov exponents, divergences, Lyapunov dimensions of the fractality, Kolmogorov-Sinai entropies, and predictability horizons are calculated. The bifurcation diagram presenting the dependence of the dynamics of the process on a small parameter determining the mode of self-organization or dynamical chaos in the cell metabolism is constructed.

The obtained theoretical results have also practical meaning, by presenting a physical interpretation of the causes for the appearance of destructive autooscillatory modes observed in biotechnological processes running in bioreactors (Section 2 and $[4,5]$ ). The variables of the mathematical model which depend on a small parameter will allow the bioengineers to skilfully control the course of a biotechnological process.

The present work was partially supported by the Program of Fundamental Research of the Department of Physics and Astronomy of the $\mathrm{Na}$ tional Academy of Sciences of Ukraine "Mathematical models of non-equilibrium process in open system" No. 0120U10085\%.

1. V.P. Gachok, V.I. Grytsay. The kinetic model of a macroporous granule with the regulation of biochemical proceses. Dokl. AN SSSR 282, No. 1, 51 (1985).

2. V.P. Gachok, V.I. Grytsay, A.Yu. Arinbasarova, A.G. Medentsev, K.A. Koshcheyenko, V.K. Akimenko. Kinetic model of hydrocortizone 1-en dehydrogenation by Arthrobacter globiformis. Biotechn. Bioengin. 33, 661 (1989).

3. V.P. Gachok, V.I. Grytsay, A.Yu. Arinbasarova, A.G. Medentsev, K.A. Koshcheyenko, V.K. Akimenko. Kinetic model for the regulation of redox reactions in steroid transformation by Arthrobacter globiformis cells. Biotechn. Bioengin. 33, 668 (1989).

4. A.G. Dorofeev, M.V. Glagolev, T.F. Bondarenko, N.S. Panikov. Unusual growth kinetics of Arthrobacter globiformis and its explanation. Mikrobiol. 61, 33 (1992).

5. A.S. Skichko. Modeling and Optimization of the Process of Cultivation of Bacteria in Bioreactors. Dissertation on the Candidate degree (Chem. Sci.) (D.I. Mendeleev Russian Chem. Techn. Univ., Moscow, 2002) (in Russian).

6. V.I. Grytsay. The self-organization in a macroporous structure of a gel with immobilized cells. The kinetic model of a bioselective membrane of a biosensor. Dopov. NAN Ukr., No. 2, 175 (2000).

ISSN 2071-0194. Ukr. J. Phys. 2020. Vol. 65, No. 5 
7. V.I. Grytsay. The self-organization in a reaction-diffusion porous medium. Dopov. NAN Ukr. No. 3, 201 (2000).

8. V.I. Grytsay. Ordered structures in the mathematical model of a biosensor. Dopov. NAN Ukr. No. 11, 112 (2000).

9. V.I. Grytsay. The self-organization of the biochemical process of immobilized cells of a bioselective membrane of a biosensor. Ukr. Fiz. Zh. 46, No. 1, 124 (2001).

10. V.I. Grytsay. Ordered and chaotic structures in the reaction-diffusion medium. Visn. Kyiv. Univ. No. 2, 394 (2002).

11. V.I. Grytsay. Conditions of self-organization of the prostacyclin-thromboxane system. Visn. Kyiv. Univ. No. 3, 372 (2002).

12. V.I. Grytsay. Modes of self-irganization in the prostacyclinthromboxane system. Visn. Kyiv. Univ. No. 4, 365 (2002).

13. V.I. Grytsay. Modeling of the processes in the polyenzymatic prostacyclin-thromboxane system. Visn. Kyiv. Univ. No. 4, 379 (2003).

14. V.V. Andreev, V.I. Grytsay. Modeling of the nonactive zones in porous granules of a catalyst and in a biosensor. Matem. Model. 17, No. 2, 57 (2005).

15. V.V. Andreev, V.I. Grytsay. Influence of the inhomogeneity of running of a diffusion-reaction process on the formation of structures in the porous medium. Matem. Model. 17, No. 6, 3 (2005).

16. V.I. Grytsay, V.V. Andreev. The role of diffusion in the formation of nonactive zones in porous reaction-diffusion media. Matem. Model. 18, No. 12, 88 (2006).

17. V. Grytsay. Unsteady conditions in porous reaction-diffusion medium. Romanian J. Biophys. 17, No. 1, 55 (2007).

18. V.I. Grytsay. Uncertainty of the evolution of structures in the reaction-diffusion medium of a bioreactor. Biofiz. Visn. Iss. 2 (19), 92 (2007).

19. V.I. Grytsay. Formation and stabilityof the morphogenetic field of immobilized cells of a bioreactor. Biofiz. Visn. Iss. 1 (20), 48 (2008).

20. V.I. Grytsay. Prediction structural instability and type attractor of biochemical process. Biofiz. Visn. Iss. 23 (2), 77 (2009).

21. V.I. Grytsay. Structural instability of a biochemical process. Ukr. J. Phys. 55 (5), 599 (2010).

22. V.I. Grytsay, I.V. Musatenko. The structure of a chaos of strange attractors within a mathematical model of the metabolism of a cell. Ukr. J. Phys. 58, No. 7, 677 (2013).

23. V.I. Grytsay, I.V. Musatenko. Self-oscillatory dynamics of the metabolic process in a cell. Ukr. Biokhim. Zh. 85, No. 2, 93 (2013).

24. V.I. Grytsay, I.V. Musatenko. A mathematical model of the metabolism of a cell. CMSIM 2, No. 4, 539 (2013).

25. V.I. Grytsay, I.V. Musatenko. Self-organization and fractality in a metabolic process of the Krebs cycle. Ukr. Biokhim. Zh. 85, No. 5, 191 (2013).

26. V.I. Grytsay, I.V. Musatenko. Self-organization and chaos in the metabolism of a cell. Biopolym. Cells. 30, No. 5, 404 (2014).

27. V. Grytsay, I. Musatenko. Nonlinear self-organization dynamics of a metabolic process of the Krebs cycle. CMSIM 3, 207 (2014).
28. V. Grytsay. Lyapunov indices and the Poincaré mapping in a study of the stability of the Krebs cycle. Ukr. J. Phys. 60, No. 6, 564 (2015).

29. V.I. Grytsay. Self-organization and fractality in the metabolic process of glycolysis. Ukr. J. Phys. 60, No. 12, 1253 (2015).

30. V. Grytsay. Self-organization and fractality created by gluconeogenesis in the metabolic process. CMSIM 5, 113 (2016).

31. V.I. Grytsay. Self-organization and chaos in the metabolism of hemostasis in a blood vessel. Ukr. J. Phys. 61, No. 7, 648 (2016).

32. V.I. Grytsay. A mathematical model of the metabolic process of atherosclerosis. Ukr. Biochem. J. 88, No. 4, 75 (2016).

33. V.I. Grytsay. Spectral analysis and invariant measure in the study of a nonlinear dynamics of the metabolic process in cells. Ukr. J. Phys. 62, No. 5, 448 (2017).

34. S.P. Kuznetsov. Dynamical Chaos (Fizmatlit, 2001) (in Russian).

35. V.P. Gachok. Strange Attractors in Biosystems (Naukova Dumka, 1989) (in Russian).

36. S.D. Varfolomeev, V.P. Gachok, A.T. Mevkh. Kinetic behavior of the multienzyme system of blood prostanoid synthesis. BioSystems. 19, 45 (1986).

37. Yu.M. Romanovskii, N.V. Stepanova, D.S. Chernavskii. Mathematical Biophysics (Nauka, 1984) (in Russian).

38. E.E. Selkov. Self-oscillations in glycolysis. Europ. J. Biochem. 4, 79 (1968).

39. G.Yu. Riznichenko. Mathematical Models in Biophysics and Ecology (Inst. of Computer. Studies, 2003) (in Russian).

40. O.P. Matyshevska, A.Yu. Karlash, Ya.V. Shtogum, A. Benilov, Yu. Kirgizov, K.O. Gorchinskyy, E.V. Buzaneva, Yu.I. Prylutskyy, P. Scharff. Self-organizing DNA/carbon nanotube molecular films. Mater. Sci. Engineer. C 15, Nos. 1-2, 249 (2001).

Received 21.11.19

\section{В.Й. Грицай, О.Г. Меденцев, Г.Ю. Арінбасарова}

АВТОКОЛИВНА ДИНАМІКА

В МАТЕМАТИЧНІЙ МОДЕЛІ МЕТАБОЛІЧНОГО ПРОЦЕСУ АЕРОБНОЇ БАКТЕРІЇ. ВПЛИВ ЦИКЛУ КРЕБСА НА САМООРГАНІЗАЦІЮ БІОСИСТЕМИ

Р е $з$ ю м е

Проведено моделювання метаболічного процесу аеробної клітини як відкритої нелінійної дисипативної системи. Побудовано карту їі метаболічних шляхів і загальну схему дисипативної системи, що приймає участь у трансформації стероїдів. Досліджено вплив циклу Кребса на динаміку в цілому метаболічного процесу, побудовано проекції фазового портрету в режимі дивного атрактора. Розраховано повні спектри показників Ляпунова, дивергенцій, ляпуновські розмірності фрактальності, ентропії Колмогорова-Сіная та горизонти передбачення в даних режимах. Побудовано біфуркаційну діаграму залежності динаміки від малого параметра, що впливає на фізичний стан системи. 